|Araştırma Makalesi / Research Article |

\title{
Üniversite Öğrencilerinde Kariyer Uyumluluğunun Yordanmasında Psikolojik ihtiyaçlar ve Azmin Rolü
}

\section{Psychological Needs and Grit Role in Predicting Career Adaptability in University Students}

\section{Ahmet Ayaz ${ }^{1}$, Hasan Eşici ${ }^{2}$}

Anahtar Kelimeler
kariyer uyumluluğu
psikolojik ihtiyaçlar
azim

\section{Keywords}

career adaptability psychological needs grit

\section{Başvuru Tarihi/Received} 01.12.2018

Kabul Tarihi /Accepted 23.01.2020
Öz

Bu araştırmanın amacı üniversite öğrencilerinin kariyer uyumluluklarının yordanmasında psikolojik ihtiyaçlar ve azmin rölünü incelemektir. Araştırma yordayıcı korelasyonel desene göre dizayn edilmiştir. Yordayıcı korelasyonel araştırmalar değişkenler arasındaki ilişkilerin incelenip, değişkenlerin birin-den yola çıkılarak diğerinin yordanmaya çalışıldığı araştırmalardır. Araştırmanın bağımlı değişkeni kariyer uyumluluğu iken bağımsız değişkenler psikolojik ihtiyaçların alt boyutlarından sevgi ve ait olma, güç, özgürlük ve eğlence ile azmin alt boyutlarından gayrette ısrar ve ilginin tutarlılığıdır. Bu araştırma 2016-2017 eğitim öğretim yılı güz döneminde Gaziantep'te bulunan Hasan Kalyoncu Üniversitesi'nde eğitim gören öğrenciler üzerinde gerçekleştirilmiştir. Çalışma grubunun belirlenmesinde uygun örnekleme yöntemi kullanılmıştır. Çalışma grubunda toplam 390 öğrenci yer almaktadır. Araştırma kapsamında, araştırmacı tarafından hazırlanan bilgi formu, Kariyer Uyum Yetenekleri Ölçeği, Temel Psikolojik İhtiyaçlar Ölçeği ve Kısa Azim Ölçeği kullanılmıştır. Kariyer uyumluluğunun yordanmasında psikolojik ihtiyaçlar ve azmin rolünün belirlenmesi amacıyla hiyerarşik regresyon analizi kullanılmıştır. Analizin ilk aşamasında modele psikolojik ihtiyaçların alt boyutlarından sevgi, özgürlük, güç ve eğlence dâhil edilmiştir. Analizin ikinci aşamasında ise modele azmin alt boyutlarından gayrette ısrar dâhil edilmiştir. Sevgi, özgürlük, güç ve eğlenceden oluşan model kariyer uyumluluğuna ilişkin varyansın \%41'ini açıklamaktadır. Analize ikinci blok olarak gayrette ısrar değişkeni dâhil edilmiştir. Gayrette ısrar değişkeni $\% 8^{\prime}$ lik manidar $(\mathrm{p}<.01)$ bir katkı sağlamaktadır. Gayrette ısrarın modele eklenmesiyle kariyer uyumluluğuna yönelik açıklanan toplam varyans \%49'a yükselmiştir.

\section{Abstract}

The aim of this research is to examine the role of psychological needs and grit of university students in predicting career adaptability. The study was designed according to the predictive correlational design. While the dependent variable of the research is career adaptability, the independent variables are love and belongingness, power, freedom and fun from the subdimensions of psychological needs; and perseverance of effort and consistency in interests from the sub-dimensions of grit. This research was conducted on the students studying at Hasan Kalyoncu University in Gaziantep in 2016-2017 academic year. The research group has been determined by purposive sampling method and consists of 390 students. The research data were collected by the prepared information form, Career Adaptability Scale, Basic Psychological Needs Scale and Short Grit Scale. Hierarchical regression analysis was used to determine the psychological needs and the role of grit in regression of career adaptability. In the first phase of the analysis, freedom, power and fun from the psychological needs significantly predicts the career adaptability. These variables are positively related to career adaptability. In the second phase of the analysis, the perseverance of effort was included in the model from the subdimensions of grit. Stimulating perseverance of effort as a means of positivity in the direction of career alignment. Varia-bles explain $49 \%$ of the total variance.

\footnotetext{
${ }^{1}$ Hasan Kayloncu Üniversitesi, Eğitim Fakültesi, Eğitim Bilimleri Bölümü, Gaziantep, TÜRKiYE; https://orcid.org/0000-0002-4081-2033

${ }^{2}$ Hasan Kayloncu Üniversitesi, Eğitim Fakültesi, Eğitim Bilimleri Bölümü, Gaziantep, TÜRKiYE; https://orcid.org/0000-0003-3659-3074
} 
Extended Abstract

\section{Introduction}

Savickas defined career adaptability as an individual's fulfillment of current developmental duties with regard to her/his career, and her/his ability to deal effectively with the career crises s/he encountered. In this context, career adaptability consists of four sub-dimensions: concern, control, curiosity, and confidence. Career adaptability has a direct positive contribution to the employment state of university students' post-graduate working life, professional identity development of students, and their reemployment. Psychological needs are among the variables that are supposed to be supporting the university students' career adaptability in their successful career patterns. Psychological needs have been described by Glasser as the core motivation factor of human-beings. These psychological needs are love and belonging, power, freedom, and fun. Glasser stated that individuals who meet their psychological needs will also be successful in their careers, and feel free, strong, and safe and be belonged. Individuals who are able to meet their psychological needs are also ready for career transitions and crises, knowing their options and making the right decisions. Grit is one of the effective factors for individuals to succeed in their careers. Grit is defined as the continuation of the work intensively despite the difficulties and the failures of the individual and the continuation of the interest for a long time. Grit brings professional success. It is seen that highly determined individuals have higher occupational successes and work for longer in their profession, have higher professional performances, are successful in coping with difficulties and challenging tasks in their business life. In this study, the explanatory power of psychological needs and grit in explaining career adaptability of university students were examined.

\section{Method}

The research was carried out according to the predictive correlational method. The predictive correlational method is the one that investigates the relationships between variables and the one in which the variables that lead to the other was predicted by another. The study group of the study consisted of 390 students. The study group was determined by purposive sampling method.

\section{Data Collection Tools}

\section{Career Adaptability Scale}

The scale was developed by Savickas and Porfeli (2012) and adapted to Turkish culture by Karacan Özdemir (2016). Confirmatory factor analysis (CFA) was performed to see if the scale had the four-factor structure as it was in its original form. When the compliance indices obtained from the DFA results were examined, it was found that the scale had a good fit with the four factors (interest, control, curiosity, confidence) $(X 2 / \mathrm{sd}=2.98, \mathrm{SRMR}=.05, \mathrm{RMSEA}=.05, \mathrm{CFI}=.90)$. In order to test the reliability of the scale, the internal consistency coefficients of the scale and the sub-dimensions were calculated. Internal consistency coefficient was calculated as .89 for the scale, .69 for the interest dimension, .82 for the control dimension, .82 for the control dimension, and .80 for the confidence dimension.

\section{Psychological Needs Scale}

The Psychological Needs Scale developed by Eşici (2014) consists of four sub-dimensions (love and belonging, freedom, power and fun) and 25 items. In the explanatory factor analysis conducted to determine the structure of the scale, a structure consisting of four sub-dimensions and explaining $48 \%$ of the variance was obtained. Confirmatory factor analysis was performed to test the four-factor constructs obtained from exploratory factor analysis. The confirmatory factor analysis results show that the scale has high compliance values $(\mathrm{X} 2 \mathrm{sd}=2.03, \mathrm{RMSEA}=.05, \mathrm{RMR}=.04, \mathrm{NFI}=.83, \mathrm{CFI}=.91, \mathrm{GFI}=.90)$. The results of test re-test analysis to determine the stability of the scale ranged from .66 to .91 while the Cronbach alpha values calculated to determine the internal consistency ranged from .66 to .87 .

\section{Short Grit Scale}

Short Grit Scale developed by Duckworth and Quinn (2009) was adapted to Turkish culture by Sarıçam et al., (2016). As a result of exploratory factor analysis performed by the researchers, they obtained a two-factor structure consisting of eight items explaining $53 \%$ of the total variance. Confirmatory factor analysis was performed to test the fit of the two-factor structure obtained after the exploratory factor analysis. The values obtained as a result of confirmatory factor analysis show that the twofactor structure has high compliance values $(X 2 / \mathrm{sd}=2.06, \mathrm{p}=.00011, \mathrm{RMSEA}=.046, \mathrm{CFI}=.95, \mathrm{GFI}=.94, \mathrm{AGFI}=.93, \mathrm{SRMR}=.047)$. When the internal consistency coefficients of the scale were examined, the coefficient for the scale's total was calculated as .83, .80 for the consistency of the interest dimension and .86 for the perseverance of effort dimension.

\section{Analysis of Data}

Hierarchical regression analysis was conducted in order to determine the role of psychological needs and grit in predicting career adaptability. First, psychological needs then grit were included in the model. In the process of preparing the data for analysis, the missing data in the dataset are examined first. In this context, binary correlations between independent variables, tolerance values, variance inflation factors (VIF) and condition index (CI) values, which are independent variables, are examined.

\section{Result and Discussion}

Hierarchical regression analysis was used to determine the explanatory level of psychological needs and grit in explaining career adaptability. In the performed hierarchical regression analysis, first psychological needs then perseverance of effort, which is one of the sub-dimensions of grit, were included in the model. The consistency of interest from the sub-dimensions of the grit 
is not included in the model because it does not significantly correlate with career adaptability. The perseverance of effort, which is the sub-dimension of grit was included in the analysis as the second block. When psychological needs are controlled, Perseverance of effort provides the model $8 \%$ contribution. In the second model, the need for freedom, power and fun among with perseverance of effort explains $49 \%$ of the career adaptability.

The results of the research show that the inclusion of psychological needs and grit in the context of the training and activities to be provided in the context of career services offered in higher education have great importance. In addition, it is recommended to examine the effect of the career adaptability development programs in this context with longitudinal investigations. The university students', participating in the program, exploring career options before graduation and taking action, finding the job after graduation, keeping the job and coping with problems that they face should be investigated through longitudinal investigations. Programs determined to be effective as a result of these researches should be implemented by university career centers. 


\section{GíRiş}

Üniversite dönemi bireyin çalışma hayatına geçişinde en önemli basamaklardan biridir. Bu dönemde öğrencilerden aldıkları teorik ve uygulamalı eğitimlerle kendilerini geliştirmeleri ve çalışma hayatına hazır hale gelmemeri beklenmektedir. Birçok öğrenci üniversite yaşamı boyunca sadece derslere girip çıkmakta ve kendini geliştirmek için herhangi bir çaba göstermemektedir (Akoğlan Kozak ve Dalkıranoğlu, 2013). Ancak iş piyasası kendini geliştiren, yeniliklere açık, uygulama deneyimi yüksek olan mezunları istihdam etme eğilimindedir (Ayaz ve Pişkin, 2017). Piyasanın bu talebi üniversite yıllarında kendini geliştirmeyen ve yenilemeyen öğrencilerin istihdam dışında kalmalarına neden olmaktadır. TÜik (2018) verilerine göre 2018 yılı genç nüfus (18-25 yaş) işsizlik oranının \%20,8 gibi büyük bir rakam çıkmasında da bu durumun etkisi olduğu yadsınamaz bir gerçektir. Üniversite yıllarında kendini geliştiren mezunlar ise diğerlerine göre çok daha kolay iş bulmakta ve kariyer yolculuklarına daha sağlıklı bir şekilde devam etmektedirler (Broadbridge ve Swansoni, 2005).

Küreselleşmenin ve teknolojik gelişmelerin hızlanması meslekler üzerinde büyük değişimlere neden olmaktadır. Mesleklerin isimleri aynı kalsa da içerikleri, eğitim gereklilikleri, görev ve sorumlulukları sürekli değişmektedir (Kim, DiPlacido, Kerns ve Darnley 2018). İş dünyasında meydana gelen bu sürekli değişim çalışanların da kendilerini geliştirmelerini zorunlu kılmaktadır. Özellikle Endüstri 4.0'a geçişin pilot uygulamalarının yapıldığı ülkemizde karanlık fabrikalardan, akıllı depolardan, yapay zeka aracılığıla iş planlama ve uygulama süreçlerinden bahsedilmektedir. Bu değişimle birlikte insan gücünden beklentiler yön değiştirmektedir (Benešová ve Tupa, 2017). Bu yön değiştirme farklı iş kollarının doğmasını ve çalışanların yönelebilecekleri yeni alanların ortaya çıkmasını sağlamaktadır (Bowker, 2004). Tüm bu göstergeler değişime ayak uydurabilen ve gerekli becerileri keşfedip kendini geliştirenlerin kariyerlerini başarıyla sürdükleri bir döneme girdiğimizi göstermektedir.

İşverenlerin günümüz çalışanlarında görmek istedikleri beceriler arasında liderlik, kültürler arası iletişim ve etkileşim, öz kontrol, sorumluluk alma, problem çözme, yaratıcılık, analitik düşünebilme, işbirliğine açık olma, esnek olma ve uyum sağlayama gibi becerilerin gerekliliğini öne çıkarmaktadır (Trilling ve Fadel, 2009; Benešová ve Tupa, 2017). Bu becerileri açıklayan temel yaklaşımlardan biri Savickas $(2005,2013)$ tarafından geliştirilen kariyer yapılandırma yaklaşımı içerisindeki kariyer uyumluluğu kavramıdır.

Savickas (2013) kariyer uyumluluğunu bireyin kariyeriyle ilgili olarak güncel gelişim görevlerini yerine getirmesi ve karşılaştı̆̆ı kariyer krizleriyle etkili bir şekilde baş etmesi olarak tanımlamıştır. Bireyler yaşam boyunca farklı kariyer geçişleri yaşamaktadır. Okul hayatından çalışma hayatına geçiş, çalışılan kurumun değiştirilmesi, aile kurma, terfi alma veya işsiz kalma gibi yaşam olayları bireyi sürekli olarak değişime uyum sağlamaya itmektedir. Tüm bu geçişlerin sağlıklı bir şekilde olması için ise önemli olan temel kavram kariyer uyumluluğudur (Savickas, 2011).

Kariyer uyumluluğu ilgi, kontrol, merak ve güven olmak üzere dört alt boyuttan oluşmaktadır (Savickas ve Porfeli, 2012). Savickas (2005)'a göre ilgi kariyer uyumluluğunun en önemli boyutudur. Bireyin geleceğini düşünmesi, geleceğiyle ilgili planlar yapması ve geleceğini önemsemesi bu boyutun altında yer almaktadır. Kontrol boyutu bireyin kariyeri üzerinde kendi kontrolü olduğuna inanması ve bunu hissetmesidir. Merak bireyin kendi potansiyeli çerçevesinde yakın ve uzak çevresinde bulunan fırsatları araştırma ve keşfetme isteği olarak tanımlanmaktadır. Son olarak güven bireyin kariyeriyle ilgili karar verme süreçlerini başarıyla yürütebileceğine ilişkin öz yeterliğini ifade etmektedir.

Kariyer uyumluluğu yüksek üniversite öğrencilerinin henüz lisans eğitimini alırken hedeflerini belirlemeledikleri, seçeneklerini araştırdıkları, eğitimler aldıkları ve gönüllü olarak çalışma hayatına dâhil oldukları görülmektedir (Duffy, 2010). Ayrıca kariyer uyumluluğu öğrencilerin mezuniyet sonrası çalışma hayatına başlama durumlarına (Guan, Guo, Bond, Cai ve ark., 2014), öğrencilerin profesyonel kimlik gelişimlerine (Guo, Guan, Yang, Xu ve ark. 2014), yeniden işe alınabilirliklerine (Koen, Klehe, Van Vianen ve ark., 2010) doğrudan pozitif katkıda bulunmaktadır. Kariyer uyumluluğu ayrıca iş stresi ve tükenmişliği azaltıcı etkiye sahiptir (Rudolph, Lavigne ve Zacher, 2017; Harry ve Coetzee, 2013).

Kariyer uyumluluğu dünyada olduğu gibi ülkemiz için de güncel ve üzerinden yoğun araştırmaların yapıldığı bir kavramdır. Kariyer uyumluluğuna ilişkin ülkemizde yapılan araştırmalar incelendiğinde kariyer uyumluluğuyla ilişkili değişkenleri belirlemeye yönelik ilişkisel araştırmalara rastlandığı gibi deneysel ve keşfedici araştırmalarla da karşılaşımıştır (Büyükgöze Kavas, 2016; Siyez ve Yusupu; 2016; Karacan Özdemir ve Güneri, 2017, Karacan Özdemir ve Ayaz, 2018, Demir ve Ayaz, 2019, Eryılmaz ve Kara, 2019). Araştırma sonuçları yüksek kariyer uyumluluğuna sahip kişilerin iş doyumu yüksek, kendini geliştiren ve yeterliklerini güncelleyen ve çağın getirdiği yeniliklere hazır bireyler olduklarını göstermektedir.

Savickas (2013) kariyer uyumluluğunun kişinin kariyeri üzerinde iki temel işlevi olduğunu belirtmektedir. Bu işlevlerden ilki kişinin kariyer gelişimiyle ilgili olarak güncel gelişim görevlerini yerine getirmesidir. Kariyer uyumluluğunun ikinci temel işlevini ise kişinin kariyerinde karşılaştığı engelleri aşabilmesidir. Kişinin kariyeriyle ilgili güncel gelişim görevlerini yerine getirebilmesi psikolojik ihtiyaçlar, karşılaştığı engelleri aşabilmesi ise azim kavramının kariyer uyumluluğunı açıklayabileceğini akla getirmektedir.

Üniversite öğrencilerinin başarılı kariyer örüntülerine sahip olmalarında kariyer uyumluluğuna olumlu katkı sağlayabilecek temel değişkenlerden biri psikolojik ihtiyaçlardır. Psikolojik ihtiyaçlar Glasser (1998; 1999; 2000) tarafından insanın temel motivasyon unsuru olarak tanımlanmıştır. Glasser'e göre insanlar acıdan kaçınan ve hazzı arttırmak isteyen varlıklardır. Acının azalması ve hazzın artması ise psikolojik ihtiyaçların karşılanması ile mümkündür. Bu psikolojik ihtiyaçlar sevgi ve ait olma, güç, özgürlük ve eğlencedir. İnsanların doğuştan sahip olduğu bu ihtiyaçlar yaşam boyunca insan davranışlarına yön vermektedir (Corey, 2015). 
Sevgi ve ait olma ihtiyacı bireyin sosyal çevresinde ve kişilerarası ilişkilerinde sevildiğine ve ilgi gördüğüne dair inancını oluşturmaktadır (Glasser, 1999). Glasser'e (2000) göre en önemli ihtiyacımız sevgi ve ait olmadır. Güç ihtiyacı, yaptığımız işlerde başarılı olma, diğer insanlara sözümüzü geçirme, başkalarından takdir ve onay alma, kendi sözümüzü başkalarına geçirme, kendini önemli hissetme isteğimizi oluşturmaktadır (Glasser, 1998; Glasser, 1999; Peterson, 2000). Glasser (1999) insanların hayatlarını kendi kontrollerinde hissettiklerinde özgürlük ihtiyaçlarını karşıladıklarını belirtmektedir. Özgürlük ihtiyacını karşılayan bireyler sağlıklı karar veren, yaratıcılığını kullanan, kendini özgür ve bağımsız hisseden bireylerdir. Eğlence ihtiyacı ise bir şeyden zevk alma, rahatlama, gülme ve öğrenmeyle karşılayabildiğimiz ihtiyacımızı oluşturmaktadır (Glasser, 1999). Eğlence ihtiyacının karşılanmasıyla bireyler yeni şeyler öğrenmeye istekli hale gelirler (Glasser, 2001).

Glasser (1999) psikolojik ihtiyaçlarını karşılayan bireylerin kendilerini özgür, güçlü, güven altında ve ait hissederek kariyerlerinde de başarılı olacaklarını belirtmiştir. Yani günlük yaşamında psikolojik ihtiyaçlarını karşılayabilen bireyler aynı zamanda kariyer görevlerini yerine getirebilen, kariyer geçişlerine hazırlıklı olan, seçeneklerini bilen ve doğru karar verebilen bireylerdir.

Bireylerin kariyerlerinde başarılı olmalarında etkili faktörlerden bir diğeri ise azimdir. Azim, bireyin karşılaştığı zorluklara ve uğradığı başarısızlıklara rağmen çalışmasına yoğun bir şekilde devam etmesi ve amacına yönelik ilgisini uzun süre devam ettirmesi olarak tanımlanmaktadır. Azimli olmayan kişi karşılaştığı zorluklarda hayal kırıklığına uğrayarak pes ederken, azimli kişi izlemesi gereken adımların farkındadır ve bunları uygulamaya devam eder (Duckworth, Peterson, Matthew ve Kelly, 2007). Azmin altında yatan temel prensip çabadır (Duckworth, 2016). Yüksek azimli birey zorluklarla karşılaşsa da bunların geçici olduğunu bilir ve bu zorlanmaların onu engellemesine izin vermez (Siddoway, 2013).

Azim mesleki başarıyıda beraberinde getirmektedir. Yüksek azimli bireylerin daha yüksek mesleki başarı gösterdikleri ve mesleklerinde daha uzun süre çalışıkları (Duckworth, Peterson, Matthew vd., 2007; Eskreis-Winkler, Shulman, Beal, Duckworth ve ark., 2014), mesleki performanslarının daha yüksek olduğu (Maddi, Matthews, Kelly ve Kelly, 2012), meslek hayatlarında karşılaştıkları olumsuzluklar ve zorlu görevlerle baş etmede daha başarılı oldukları (De Vera, Gavino ve Portugal, 2015) görülmektedir.

Günümüzün önemli becerileri arasında yer alan kariyer uyumluluğu özellikle üniversiteden iş hayatına geçiş sürecinde işlevsel bir role sahiptir. Özellikle ülkemizde gerçekleştirilen "Dijital Dönüşüm” hamleleri çalışanlardan beklentileri de değiştirecektir. Gaziantep ili de Türkiye'nin Dijital Dönüşüm sürecinde uygulamaların yapılacağı pilot illerden biridir. Gaziantep'in büyüyen sanayi ve ticaret hacmi ve Endüstri 4.0. ile entegre edilen işletme sayısının artış göstermesi durumunda yeni ve çağın gerekliliklerine uygun istihdama ihtiyaç duyacağı açık bir gerçektir. Nitekim bölgedeki önemli işletmelerin yöneticileri istedikleri çalışan profilini kendini geliştiren, yeniliklere açık, uyumlu ve esnek özelliklere sahip kişiler olarak betimlemektedir (Ayaz ve Pişkin, 2017). Üniversite öğrencilerinin bu geçişe hazır olmalarını sağlayacakları en önemli becerilerden biri de kariyer uyumluluklarıdır. Üniversitelerde uygulanan kariyer uyumluluğunu geliştirmeye yönelik çalışmalarda öğrencilerin kariyer farkındalıklarının yüksek olması, kendi kararlarını verebiliyor olmaları, seçeneklerini araştırıyor olmaları ve karşılaştıkları engelleri aşabiliyor olmaları hedeflenmektedir. Kariyer uyumluluğunun dört alt boyutunu temsil eden bu özelliklerin gelişimini hızlandıracak, kolaylaştıracak ve daha kalıcı hale getirecek değişkenlerin keşfedilmesi ise öğrencilere uygulanacak programların içeriğinden niteliğine birçok faktörü şekillendirecektir. Kariyer uyumluluğunu açıklayan özelliklerin keşfedilmesinin amaçlandığı bu araştırmadan elde edilecek sonuçlar öğrencilerin üniversiteden işe hayatına geçiş süreçlerinde kariyer uyumluluklarını nasıl geliştirebiliriz sorusuna cevap olacaktır. Bu bağlamda bu araştırmada üniversite öğrencilerinde kariyer uyumluluğunun psikolojik ihtiyaçlar ve azmin tarafından açıklanabilirliğini tespit etmek amaçlanmıştır.

\section{YÖNTEM}

\section{Araştırma Deseni}

Bu araştırma yordayıcı korelasyonel modele bağlı olarak gerçekleştirilmiştir. Frankel ve Wallen (2009) yordayıcı korelasyonel araştırmaları değişkenler arasındaki ilişkilerin incelenip, değişkenlerin birinden yola çıkılarak diğerinin yardanmaya çalışıldı̆̆ı araştırmalar olarak tanımlamaktadırlar. Bu bağlamda araştırmanın bağımlı değişkeni kariyer uyumluluğu iken bağımsız değişkenler psikolojik ihtiyaçlar ve azimdir. Psikolojik intiyaçlar sevme ve ait olma, güç, özgürlük ve eğlence alt boyutlarından oluşmaktayken, azim gayrette ısrar ve ilginin tutarlılığı alt boyutlarından oluşmaktadır.

\section{Çalışma Grubu}

Araştırmanın çalışma grubunu Hasan Kalyoncu Üniversitesi'nde eğitim gören 390 öğrenci oluşturmaktadır. Çalışma grubu amaçsal örnekleme yöntemlerinden maksimum çeşitlilik örnekleme yöntemi ile belirlenmiştir. Maksimum çeşitlilik örnekleme yönteminde araştırmacı problemin daha geniş bir çerçevede betimlenmesi amacıyla çalışma grubuna farklı grupları temsil edecek kişileri dâhil etmektedir (Büyüköztürk, Kılıç Çakmak, Akgün, Karadeniz ve Demirel, 2017). Veri toplama sürecinin tamamlanmasının ardından ölçme araçlarını inceleme süreci başlamıştır. Bu kapsamda veri aracını tamamlamadığı tespit edilen dört katılımcı araştırma grubundan çıkartılmıştır. Nihai çalışma grubu 386 kişiden oluşmaktadır. Çalışma grubuna ait betimsel bilgiler Tablo 1' de sunulmuştur. 
Tablo 1. Çalışma grubuna ilişkin betimsel bilgiler

\begin{tabular}{|c|c|c|c|}
\hline Değişkenler & Kategoriler & $\mathbf{N}$ & $\%$ \\
\hline & Erkek & 152 & 39,4 \\
\hline \multicolumn{4}{|l|}{ Cinsiyet } \\
\hline & Kadın & 234 & 60,6 \\
\hline \multirow{5}{*}{ Eğitim Görülen Program } & Beslenme ve Diyetetik & 81 & 21 \\
\hline & İnşaat Mühendisliği & 62 & 16,1 \\
\hline & Siyaset Bilimi ve Uluslararası İlişkiler & 28 & 7,3 \\
\hline & İşletme-iktisat & 68 & 17,6 \\
\hline & Rehberlik ve Psikolojik Danışmanlık & 147 & 38,1 \\
\hline \multirow{5}{*}{ Sınıf Düzeyi } & 1. Sinıf & 148 & 38,3 \\
\hline & 2. Sinıf & 44 & 11,4 \\
\hline & & & \\
\hline & 3. Sinıf & 111 & 28,8 \\
\hline & 4. Sinıf & 83 & 21,5 \\
\hline
\end{tabular}

Tablo 1 incelendiğinde çalışma grubunda yer alan öğrencilerin 152'sinin $(\% 39,4)$ erkek, 234'ünün (\%60,6) kadın olduğu görülmektedir. Ayrıca 81 öğrenci (\%21) Beslenme ve Diyetetik, 62 öğrenci $(\% 16,1)$ İnşaat Mühendisliği, 28 öğrenci (\%7,3) Siyaset Bilimi ve Uluslarası ílişkiler, 68 öğrenci $(\% 17,6)$ İşletme-iktisat ve son olarak 147 öğrenci $(\% 38,1)$ Rehberlik ve Psikolojik Danışmanlık programında eğitim görmektedir. Çalışma grubundaki öğrencilerin sınıf düzeylerine bakıldığında ise 1.sınıfta eğitim gören 148 (\%38,1), 2.sınıfta eğitim gören $44(\% 11,4)$, 3.sınıfta eğitim gören $111(\% 28,8)$ ve 4. sınıfta eğitim gören 83 (\%21,5) öğrenci bulunmaktadır.

\section{Veri Toplama Araçları}

Araştırma kapsamında Savickas ve Porfeli (2012) tarafından geliştirilen ve Karacan Özdemir (2016) tarafından uyarlanan Kariyer Uyum Yetenekleri Ölçeği, Eşici (2014) tarafından geliştirilen Psikolojik ihtiyaçlar Ölçeği, Duckworth ve Quinn (2009) tarafından geliştirilen ve Sarıçam, Çelik ve Oğuz (2016) tarafından uyarlanan Kısa Azim Ölçeği ve araştırmacılar tarafından geliştirilen Kişisel Bilgi Formu kullanılmıştır. Ölçme araçlarına ilişkin detaylı bilgiler aşağıda yer almaktadır.

\section{Kariyer Uyum Yetenekleri Ölçeği}

Araştırma kapsamında Savickas ve Porfeli (2012) tarafından geliştirilen ve Karacan Özdemir (2016) tarafından Türk kültürüne uyarlaması yapılan kariyer uyum yetenekleri ölçeği kullanılmıştır. Ölçeğin orijinal formunda olduğu gibi dört faktörlü yapıya sahip olup olmadığını anlamak amacıyla doğrulayıcı faktör analizi (DFA) gerçekleştirilmiştir. Yapılan DFA sonuçlarında elde edilen uyum indeksleri incelendiğinde ölçeğin dört faktörlü (ilgi, kontrol, merak, güven) yapı üzerinden iyi bir uyum gösterdiği anlaşılmaktadır $(\chi 2 / s d=2.98, \mathrm{SRMR}=.05, \mathrm{RMSEA}=.05, \mathrm{CFI}=.90)$. Ölçeğin güvenirliği test etmek amacıyla ölçeğin tamamına ve alt boyutlara ait iç tutarlılık katsyıları hesaplanmıştır. İç tutarlılık katsayısı ölçeğin tamamında .89 iken, ilgi boyutunda .69, kontrol boyutunda .71 merak boyutunda .82 ve güven boyutunda ise .80 olarak hesaplanmıştır.

\section{Psikolojik İhtiyaçlar Ölçeği}

Eşici (2014) tarafından geliştirilen Psikolojik ihtiyaçlar Ölçeği dört alt boyuttan (sevgi ve ait olma, özgürlük, güç ve eğlence) ve 25 maddeden oluşmaktadır. Ölçeğin yapısını belirlemek amacıyla gerçekleştirilen açımlayıcı faktör analizinde dört alt boyuttan oluşan ve varyansın \%48'ini açıklayan bir yapı elde edilmiştir. Açımlayıcı faktör analizinde elde edilen dört faktörlü yapıyı test etmek amacıyla doğrulayıcı faktör analizi gerçekleştirilmiştir. Doğrulayıcı faktör analizi sonuçları ölçeğin yüksek uyum değerlerine sahip olduğunu göstermektedir ( $\chi 2 / s d=2.03, \mathrm{RMSEA}=.05, \mathrm{RMR}=.04, \mathrm{NFI}=.83, \mathrm{CFI}=.91, \mathrm{GFI}=.90)$. Ölçeğin kararlılığını tespit etmek amacıyla yapılan test tekrar test analizi sonuçları .66 ile .91 arasında değişirken iç tutarılıı̆ını tespit etmek amacıyla hesaplanan crombach alfa değerleri .66 ile .87 arasında değişmektedir.

\section{Kısa Azim Ölçeği}

Duckworth ve Quinn (2009) tarafından geliştirilen Kısa Azim Ölçeği Sarıçam, Çelik ve Oğuz (2016) tarafından Türk kültürüne uyarlanmıştır. Araştırmacılar gerçekleştirdikleri açımlayıcı faktör analizi sonucunda toplam varyansın \%53'ünü açıklayan sekiz maddeden oluşan iki faktörlü bir yapı elde etmişlerdir. Açımlayıcı faktör analizi sonrasında elde edilen iki faktörlü yapının uyumluluğunu test etmek amacıyla doğrulayıcı faktör analizi gerçekleştirilmiştir. Doğrulayıcı faktör analizi sonucunda elde edilen değerler $(\chi 2 / \mathrm{sd}=2.06, \mathrm{p}=.00011, \mathrm{RMSEA}=.046, \mathrm{CFI}=.95, \mathrm{GFI}=.94, \mathrm{AGFI}=.93, \mathrm{SRMR}=.047)$ iki faktörlü yapının uyum değerlerinin yüksek olduğunu göstermektedir. Ölçeğin iç tutarlılık katsayıları incelendiğinde ise ölçeğin tamamına ilişkin katsayı .83, ilginin tutarlılığı boyutu için .80 ve gayrette ısrar boyutu için .86 olarak hesaplanmıştır. 


\section{Verilerin Analizi ve Yorumlanması}

Araştırma kapsamında betimleyici bilgileri tespit etmek amacıyla frekans analizi gerçekleştirilmiştir. Kariyer uyumluluğunun yordanmasında psikolojik ihtiyaçlar ve azmin rolünü tespit etmek amacıyla ise hiyerarşik regresyon analizi yapılmıştır. Modele ilk önce psikolojik ihtiyaçlar daha sonra ise azim dahil edilmiştir.

Verileri analize hazırlama sürecinde ilk olarak veri setinde yeralan kayıp veriler incelenmiştir. Ölçme araçlarını belirgin bir şekilde boş bıraktığı tespit edilen dört katılımcı veri setinden çıkartılmıştır. Kalan katılımcıların verdiği cevaplardaki kayıp değerlerin \%0 ile \%2,6 arasında değişiklik gösterdiği tespit edilmiştir. Ayrıca kayıp verilerin sistematik bir dağılım göstermediği de görülmektedir. Yapılan analizlerde veri kaybı olmaması için Tabachnick ve Fidell (2015) tarafından yansız kayıp verilerin ataması için kullanılması önerilen beklenti yükseltme yöntemiyle kayıp veri ataması gerçekleştirilmiştir.

Kayıp veri atamasının yapılmasının ardından veri setinde yeralan sapkın değerler tek boyutlu ve çok boyutlu olarak belirlenmiştir. Hesaplanan z puanları sonrasında $-3+3$ aralığının dışında kalan 11 katılımcı ve mahalabonis uzaklığı değerleri incelendiğinde .001 'den küçük değer veren iki katılımcı veri setinden çıkartılmıştır.

Verilerin analizi uygunluğu tespit etmek amacıyla son olarak değişkenler arasındaki çoklu bağlantılılık sorunu incelenmiştir. Çoklu bağlantılılık iki değişken arasında yüksek düzeyde ilişkinin olduğu durumlarda ortaya çıkan bir problemdir (Büyüköztürk, 2017). Bu bağlamda bağımsız değişkenler arasındaki ikili korelasyonlar, bağımsız değişkenlerin açıklayamadıkları varyans olan tolerans değerleri, varyans büyütme faktörleri (VIF) ve durum indeks (CI) değerleri incelenmiştir. Tablo 2 incelendiğinde değişkenler arasında çoklu bağlantılılık sorununun olmadığı görülmektedir.

Tablo 2. Araştırma Kapsamında İncelenen Değişkenlere Yönelik Çoklu Bağlantılılık Sorununun İncelenmesine Yönelik Değerler

\begin{tabular}{|c|c|c|c|c|c|c|}
\hline Model & Değişkenler & İkili r & Kısmı r & Tolerans & VIF & $\mathrm{Cl}$ \\
\hline \multirow{4}{*}{1} & Sevme ait olma & 0.167 & 0.001 & 0.898 & 1.114 & 14.461 \\
\hline & Özgürlük & 0.397 & 0.188 & 0.806 & 1.241 & 17.861 \\
\hline & Güç & 0.555 & 0.352 & 0.668 & 1.496 & 20.003 \\
\hline & Eğlence & 0.504 & 0.305 & 0.75 & 1.333 & 26.264 \\
\hline \multirow{5}{*}{2} & Sevme ait olma & 0.167 & 0.014 & 0.897 & 1.115 & 15.023 \\
\hline & Özgürlük & 0.397 & 0.135 & 0.783 & 1.277 & 18.01 \\
\hline & Güç & 0.555 & 0.261 & 0.61 & 1.639 & 20.46 \\
\hline & Eğlence & 0.504 & 0.230 & 0.705 & 1.419 & 22.4 \\
\hline & Gayrette Israr & 0.588 & 0.364 & 0.688 & 1.452 & 28.781 \\
\hline
\end{tabular}

Tablo 2 incelendiğinde bağımsız değişkenler arasındaki ikili korelasonların tamamının .80 den küçük olduğu görülmektedir. Değişkenlerin tolerans değerlerinin .20'den daha yüksek olduğu görülmektedir. Değişkenlerin varyans büyütme faktörü (VIF) değerlerine bakıldığında 10' dan yüksek herhangi bir değere rastlanmamıştır. Son olarak değişkenlerin durum indeks (Cl) değerleri incelendiğinde 30'dan yüksek bir değere rastlanmamıştır. Elde edilen sonuçlar değişkenlere ilişkin çoklu bağlantılılık sorununun olmadığını göstermektedir (Büyüköztürk, 2017).

\section{BULGULAR}

Araştırma bulguları iki bölüm altında incelenmiştir. İlk bölümde Kariyer Uyumluluğu, Psikolojik İhtiyaçlar ve Azim arasındaki ilişkiye ilişkin bulgular yer alırken, ikinci bölümde Kariyer Uyumluluğunun Psikolojik İhtiyaçlar ve Azmin tarafından açıklanma durumuna ilişkin hiyerarşik regresyon analizi sonuçları bulunmaktadır.

\section{Kariyer Uyumluluğu, Psikolojik ìtiyaçlar ve Azim Arasındaki iliş̧inin İncelenmesi}

Hiyerarşik regresyon analizi yapılmadan önce araştırma kapsamında incelenen değişkenler arasındaki korelasyon katsayıları incelenmiştir. Tablo 3 incelendiğinde Kariyer Uyumluluğu toplam puanı ile psikolojik ihtiyaçlar ve azim arasındaki korelasyon katsayılarının .17 ile .59 arasında değişiklik gösterdiği görülmektedir. Kariyer Uyumluluğu toplam puanı temel psikolojik ihtiyaçların alt boyuları arasındaki ilişki katsayıları; sevme ait olma ihtiyacı ile .17, özgürlük ihtiyacı ile .40, güç ihtiyacı ile .55, eğlence ihtiyacı ile .50 olarak hesaplanmıştır. Kariyer uyumluluğu ile azmin alt boyutları arasındaki ilişki incelendiğinde gayrette ısrar ile kariyer uyumluluğu toplam puanı arasındaki ilişkinin .59 olduğu tespit edilirken, ilginin tutarlılığı alt boyutunun manidar bir ilişki göstermediği tespit edilmiştir. 
Tablo 3. Araştırma Kapsamında İncelenen DeğişkenlerArasındaki Korelasyon Katsayıları

\begin{tabular}{|c|c|c|c|c|c|c|c|c|c|c|c|c|c|}
\hline Değişkenler & 1 & 2 & 3 & 4 & 5 & 6 & 7 & 8 & 9 & 10 & 11 & 12 & 13 \\
\hline İlgi (1) & 1 & & & & & & & & & & & & \\
\hline Kontrol (2) & $.56 * *$ & 1 & & & & & & & & & & & \\
\hline Merak (3) & $59 * *$ & $.56 * *$ & 1 & & & & & & & & & & \\
\hline Güven (4) & $62^{* *}$ & $.62^{* *}$ & $.72 * *$ & 1 & & & & & & & & & \\
\hline KU (5) & $82^{* *}$ & $.81^{* *}$ & $.86^{* *}$ & $.88^{* *}$ & 1 & & & & & & & & \\
\hline Sevgi (6) & $.20 * *$ & $.17^{* *}$ & .05 & $.16^{* *}$ & $.17^{* *}$ & 1 & & & & & & & \\
\hline Özgürlük (7) & $.26^{* *}$ & $.45^{* *}$ & $.32 * *$ & $.31 * *$ & $.40 * *$ & .02 & 1 & & & & & & \\
\hline Güç (8) & $.43^{* *}$ & $.50 * *$ & $.46^{* *}$ & $.48^{* *}$ & $.55^{* *}$ & $.29 * *$ & $.40^{* *}$ & 1 & & & & & \\
\hline Eğlence (9) & $.40 * *$ & $.41^{* *}$ & $.42^{* *}$ & $.47^{* *}$ & $.50 * *$ & $.21^{* *}$ & $.32^{* *}$ & $.47^{* *}$ & 1 & & & & \\
\hline pi (10) & $.48^{* *}$ & $.54 * *$ & $.43 * *$ & $.51 * *$ & $.58^{* *}$ & $.63^{* *}$ & $.57^{* *}$ & $.75^{* *}$ & $.75^{* *}$ & 1 & & & \\
\hline іт (11) & .08 & .03 & -.02 & .06 & .04 & .07 & -.07 & .01 & -.02 & .01 & 1 & & \\
\hline GI (12) & $.47^{* *}$ & $.54 * *$ & $.43^{* *}$ & $.55^{* *}$ & $.59 * *$ & $.12^{*}$ & $.36 * *$ & $.48^{* *}$ & $.44^{* *}$ & $.49 * *$ & .07 & 1 & \\
\hline Azim (13) & $.36 * *$ & $.38 * *$ & $.26 * *$ & $.40 * *$ & $.41 * *$ & $.12 *$ & $.18^{* *}$ & $.31 * *$ & $.27^{* *}$ & $.32 * *$ & $.77^{* *}$ & $.69 * *$ & 1 \\
\hline
\end{tabular}

**p<.01 KU: Kariyer Uyumluluğu Pi: Psikolojik Ihityaçlar $\quad$ iT: ilgilerin Tutarlılığı $\quad$ GI: Gayrette Israr

\section{Kariyer Uyumluluğunun Yordanmasında Psikolojik İhtiyaçlar ve Azmin Rolü}

Psikolojik ihtiyaçlar ve azmin kariyer uyumluluğunu açıklama düzeylerinin belirlenmesi amacıyla gerçekleştirilen hiyerarşik regresyon analizi sonuçları Tablo 4'de verilmiştir. Gerçekleştirilen hiyerarşik regresyon analizinde modele öncelikle psikolojik intiyaçlar, sonrasında ise azmin alt boyutlarından gayrette ısrar dahil edilmiştir. Azmin alt boyutlarından ilginin tutarılıı̆ı ise kariyer uyumluluğu ile manidar bir ilişki göstermediğinden modele dahil edilmemiştir.

Birinci modelde sevme ve ait olma, güç, özgürlük ve eğlence ihtiyaçları yer almaktadır. Tablo 4 incelendiğinde özgürlük, güç ve eğlence ihtiyaçlarının kariyer uyumluluğunun manidar yordayıcıları olduğu görülürken sevme ve ait olma ihtiyacının kariyer uyumluluğunun manidar yordayıcısı olmadığı tespit edilmiştir. Psikolojik ihtiyaçlar kariyer uyumluluğunun \%41'ini açıklama gücüne sahiptir. İlk modelin en güçlü yordayıcısı güç ihtiyacıdır. Güç ihtiyacını eğlence ve özgürlük ihtiyaçları takip etmektedir.

Tablo 4. Kariyer Uyumluluğu Yordanmasına İlişkin Hiyerarşik Regresyon Analizi Sonuçları

\begin{tabular}{|c|c|c|c|c|c|c|}
\hline Model & Yordayıcı & B & $\mathrm{SH}_{\mathrm{B}}$ & $\beta$ & $\mathbf{R}^{2}$ & $\Delta / R^{2}$ \\
\hline \multirow{5}{*}{1} & Sabit & 13.723 & 5.872 & - & \multirow{5}{*}{. .41} & \multirow{5}{*}{. $.41^{* *}$} \\
\hline & Sevme ve Ait Olma & .003 & .131 & 001 & & \\
\hline & Özgürlük & .758 & .207 & $.164 * *$ & & \\
\hline & Güç & 1.623 & .225 & $355^{* *}$ & & \\
\hline & Eğlence & .931 & .152 & $.285^{* *}$ & & \\
\hline \multirow{6}{*}{2} & Sabit & 8.116 & 5.527 & & \multirow{6}{*}{. .49} & \multirow{6}{*}{$.08 * *$} \\
\hline & Sevme ve Ait Olma & 0.033 & 0.122 & 0.011 & & \\
\hline & Özgürlük & 0.511 & 0.195 & $0.111^{* *}$ & & \\
\hline & Güç & 1.138 & 0.219 & $0.249 * *$ & & \\
\hline & Eğlence & 0.661 & 0.146 & $0.202 * *$ & & \\
\hline & Gayrette Israr & 1.801 & 0.24 & $0.338 * *$ & & \\
\hline
\end{tabular}

$* * \mathrm{p}<.01$

Analizin ikinci aşamasında modele azmin alt boyutlarından gayrette ısrar dahil edilmiştir. Psikolojik ihtiyaçlar sabit tutulduğunda azmin alt boyutlarından gayrette ısrar modele \%8'lik manidar bir katkı sağlamaktadır. ilk modelde kariyer uyumluluğu üzerinde manidar bir katkısı olmayan sevme ve ait olma ihtiyacı ikinci modelde de manidar bir katkı sunmamaktadır. Özgürlük, güç ve eğlence ihtiyacı gayrette ısrarla birlikte kariyer uyumluluğunun \%49'unu açıklamaktadır. 


\section{TARTIŞMA}

Araştırma sonucunda arasında psikolojik ihtiyaçların alt boyutlarından özgürlük, güç ve eğlence ihtiyaçları ile azmin alt boyutlarından gayrette ısrarın kariyer uyumluluğunun manidar yordayıcıları olduğu tespit edilmiştir. Psikolojik ihtiyaçlar arasında yer alan sevme ve ait olma ihtiyacı ile azmin alt boyutlarından ilginin tutarlılı̆ı kariyer uyumluluğunun manidar yordayıcılarından değiltir.

Kariyer uyumluluğu dört alt boyuttan oluşan ve yüksek olması durumunda kişinin kariyerini başarıyla yönetmesini sağlayan bir kavramdır. Kişinin geleceğiyle ilgilenmeye başlaması, kariyerini kontrol etmesi, seçeneklerini keşfetmesi ve karşılaştığı engelleri aşabilmesi kariyer uyumluluğunun yüksekliğinin göstergesidir. Araştırma sonuçlarına göre kariyer uyumluluğunun en güçlü yordayıcısı güç ihtiyacıdır. Güç ihtiyacı özellikle üniversite dönemindeki bireylerde kişinin yetkinlik ve kontrol algılarının yüksekliğiyle ilişkilendirilebilir. Güç ihtiyacını karşılayan kişiler günlük yaşamlarından bağımsız olmayan kariyerlerinde de kontrolü kendi ellerinde hissetmektedirler. Savickas'a $(2005 ; 2013)$ göre ise kariyer uyumluluğu yüksek kişiler kendi kariyer kararlarını verebilmekte ve kendi kariyerlerini kendileri yapılandırmaktadırlar. Bu durum Glasser'in (1999) belirttiği güç ihtiyacının karşılanması ile örtüşmektedir. Güç ihtiyacının karşılayan kişiler kendi kararlarını verebileceğine inanan, kendini yetkin ve başarılı gören kişilerdir. Aynı zamanda güç ihtiyacını karşılayan kişilerin kendi kariyerlerini yapılandırdıklarını söylemek de mümkündür. Güç ihtiyacını karşılayan bireyler aynı zamanda karşılaştığı problemleri aşmada da yetkindirler (Glasser, 1999). Kuramsal görüşler ele alındı̆̆ında ortaya çıkan sonuç araştırma sonuçlarını destekler niteliktedir. Güç ihtiyacı kişiye sağladığı yetkinlik ve yeterlik algısı ile kariyer uyumluluğunun kontrol, problem çözme becerisi ile ise güven boyutunu destekler niteliktedir. Kariyer uyumluluğunun diğer manidar yordayıcıları arasında ise özgürlük ihtiyacıdır. Kişinin seçeneklerini araştırmada ve uygulamaya geçirmede özgür olduğunu hissetmesi bu ihtiyacın temel doyum kaynağıdır. Üniversiteye yerleşen ve lisans eğitimine başlayan öğrenciler süreç içerisinde mezuniyet sonrası çalışma alanlarını keşfetmeye başlamaktadırlar. Farklı alternatifler üretebilen, bu alternatifleri deneyimleyen ve değerlendirebilen kişiler özellikle kariyer uyumluluğunun merak boyutunda yetkindirler (Savickas, 2005; 2013) . Kişinin seçeneklerini üretebilmesi ve bu seçenekleri değerlendirebilmesi için ise özgür olduğunu hissetmesine yani özgürlük ihtiyacını doyurması gerekmektedir (Glasser, 1999). Ayrıca Wubbolding'e (2013) göre özgürlük ihtiyacını karşılayan kişiler seçeneklerini keşfetmeye açık olan kişilerdir. Araştırma sonucuna göre özgürlük ihtiyacının tatmin edilmesinin kariyer uyumluluğunun manidar açıklayıcısı olması bu kuramsal görüşleri destekler niteliktedir. Kariyer uyumluluğunun bir diğer yordayıcısı eğlence ihtiyacıdır. Eğlence ihtiyacı iki boyutta ele alınmaktadır. İlk boyut kişinin eğlenmesi ve keyif almasıyken, ikinci boyut öğrenme deneyimlerinin zenginliği ve bu deneyimlerden alınan keyif ile ilgilidir (Wubbolding, 1999). Yeni deneyimlerden keyif alan ve öğrenmeye açık olan bir üniversite öğrencisi kariyerindeki yeniliklere daha kolay uyum sağlayacak ve karşılaşacağı yenilenme sürecini tehdit olarak görmek yerine bir öğrenme fırsatı olarak yorumlayacaktır. Savickas'ın (2005; 2013) belirttiği gibi kariyer uyumluluğu kişinin güncel kariyer görevlerini yerine getirmesi ve karşılaştığı engelleri aşabilme kapasitesidir. Eğlence ihtiyacının doyurulması kişinin karşılaştığı engelleri öğrenme fırsatı olarak değerlendirmesini sağlayarak kariyer uyumluluğuna katkı sağlamaktadır. Araştırma sonucu elde edilen bulgu kuramsal bilgiler ışığında desteklenir niteliktedir.

Kuramsal bilgilere ek olarak psikolojik ihtiyaçların doyurulmasının kişilerin kariyer yaşantıları üzerine olumlu etkilelerini göstererek araştırma sonuçlarını destekleyen çalışmalar da mevcuttur. Broeck, Vanteenkiste De Witte ve Lens'e (2008) göre psikolojik intiyaçların doyurulması mesleki tükenmişliği azaltmakta ve çalışanların işe yönelik zindeliğini arttırmaktadır. Benzer şekilde psikolojik ihtiyaçların doyumu arttıkça çalışanların işe bağılıkları artmakta, işten ayrılma niyetleri ise azalmaktadır (Silman, 2014; Verbruggen, Cooman ve Vansteenkiste, 2015). Arshadi'ye (2010) göre ise psikolojik ihtiyaçların doyurulması kişinin işine yönelik motivasyonunu ve iş performansını olumlu etkileyen önemli faktörler arasındadır. Özgürlük ve güç ihtiyacının karşılanması kişinin yaptığı işi mecburiyet olarak görmesini engellemekte ve kişiler işlerini zevk alarak yapmaktadır (Andreassen, Hetland, ve Pallesen, 2010). Tüm bu çalışmalar psikolojik ihtiyaçlar doyuruldukça kişilerin kariyerlerinin olumlu etkilendiğini göstermektedir.

Araştırmadan elde edilen bir diğer bulgu azmin alt boyutlarından gayrette ısrarın kariyer uyumluluğunun manidar yordayıcısı olduğu şeklindedir. Kariyer uyumluluğuna ilişkin kuramsal bilgiler (Savickas, 2005; Savickas ve Porfeli, 2011; Savickas; 2013) bu bulguyu destekler niteliktedir. Kariyer uyumluluğu yüksek kişiler karşılaştıkları problemler karşısında pes etmeden çözüme ulaşma yolunda ilerlemektedirler (Savickas, 2005; Savickas ve Porfeli, 2011; Savickas; 2013). Karşılaştığı engel ne olursa olsun çözüm bulmayı amaçlayan ve bunun için içsel ve dışsal gerekli mekanizmalarını harekete geçiren kişiler aynı zamanda yüksek azim gösteren kişilerdir. Yüksek azimli kişiler benzer şekilde kolay pes etmeyen ve karşılaştıkları sorunları çözebilen kişilerdir (Duckwort ve Peterson, 2007; Duckwort, 2016; Maddi ve ark., 2012). Yüksek azimli kişilerin önemli özelliklerinden biri geleceğe yönelik hedefler koymaları, bu hedefleri belirlemek için planlar yapmalarıdır (Duckwort ve Peterson, 2007; Hogan ve Larkin-Wong, 2013). Kariyer uyumluluğunun temelinde ise kişinin geleceğini düşünmesi, geleceğiyle ilgili planlamalar yapması yer almaktadır (Savickas, 2005; Savickas ve Porfeli, 2011; Savickas; 2013). Üniversite hayatında karşılaştığı engelleri aşabileceğine dair inancı olan öğrencinin pes etmemesi, çözüm arayışına girmesi ve alternatifler üretebilmesi kariyer uyumluluğunu da geliştiren temel ögelerdendir. Bu sonuç aynı zamanda engeller karşısında pes etmemeyi öğrenen öğrencilerin çalışma hayatında da başarıya ulaşabileceğinin göstergesidir.

Azmin kariyer uyumluluğunun manidar yordayıcısı olduğuna dair elde edilen bulgu farklı araştırma sonuçlarınca da desteklenmektedir. Azim mesleki başarıyı beraberinde getirdiği gibi (Franklin, 2015; Duckworth, Quinn ve Seligman, 2009), kişinin mesleğinde daha uzun süre çalışma eğilimi göstermesine (Duckworth ve Peterson; 2007) ve bireylerin kariyerlerinde karşılaştıkları problemlerle daha etkili bir şekilde baş etmelerini sağlamaktadır (De Vera, Gavino ve Portugal, 2015; Hogan ve Larkin-Wong, 2013). Bunlara ek olarak yüksek azimli çalışanların değişime daha kolay uyum sağladıkları ve yeniliklere açık konumda oldukları (Hogan

| Kastamonu Eğitim Dergisi, 2020, Vol. 28, No. 3| 
ve Larkin-Wong, 2013) ve kurumsal aidiyetlerinin daha yüksek olduğunu (Suzuki, Tamesue, Asahi ve Ishikawa, 2015) gösteren araştırmalar da bulunmaktadır. Yani azmin yüksekliği kişinin daha esnek olmasını, karşılaştığı engelleri daha kolay aşmasını, değişikliklere daha rahat uyum sağlamasını ve sonuç olarak kariyer uyumluluğunun daha yüksek olmasını sağlamaktadır.

\section{SONUÇ VE ÖNERILER}

Araştırma sonucunda üniversite öğrencilerin kariyer uyumluluklarının psikolojik ihtiyaçlardan güç, özgürlük ve eğlence ve azmin alt boyutlarından gayrette ısrar ile açıklanabildiği tespit edilmiştir. Bu sonuç üniversite öğrencilerinin özellikle ülkemizin içinde bulunduğu Dijital Dönüşüm sürecinine geçişte kendilerini yenileme sürecinin psikolojik ihtiyaçlar ve azimden bağımsız bir şekilde yapılmaması gerektiğini göstermetkedir. Araştırma sonucunda elde edilen bulgular bağlamında sunulan öneriler araştırmacılara yönelik ve uygulayıcılara yönelik olarak iki kısımda ele alınmıştır. Araştırma sonucunda güç, özgürlük ve eğlence ihtiyaçları ve azmin alt boyutlarından gayrette ısrarın kariyer uyumluğunun manidar yordayıcıları olduğu bulgusu elde edilmiştir. Üniversite öğrencileri üzerinden elde edilen bu bulgunun çalışma hayatındaki karşılığının keşfetmek üzere üniversiteden çalışmaya hayatına geçiş sürecinde kariyer uyumluluğunun rolünün keşfedildiği ve bu bağlamda psikolojik ihtiyaçlar ve azmin incelendiği nitel çalışmaların yapılması araştırmacılara önerilmektedir. Kuramsal açıdan kişiyi harekete geçirici rolde olan psikolojik ihtiyaçlar kariyer değerleri olarak ele alındığı ve kişilerin çalışma hayatlarında önem verdikleri ve tatmin ettikleri ihtiyaçların ortaya çıkardığı sonuçların kariyer uyumluluğu açısından incelenmesi araştırmacılara önerilmektedir. Bu bağlamda seçim teorisinde yeralan psikolojik ihtiyaçların temel alındığı bir kariyer değerleri ölçeğinin geliştirilmesi kariyer literatürüne önemli katkılar sağlayacaktır. Ayrıca üniversite dönemindeki öğrencilerin üniversiteye başlangıçlarından itibaren kariyer uyumluluklarını etkileyen psikolojik ihtiyaçlar, azim gibi kavramlar bağlamındaki gelişimlerinin boylamsal çalışmalarla incelenmesi araştırmacılara sunulan bir diğer öneridir. Araştırma kapsamında kullanılan azim ölçeğinin bir alt boyutu gerçekleştirilen doğrulayıcı faktör analizi sonucunda çalışmamıştır. Bu bağlamda Türk kültürünü yansıtan bir azim ölçeğinin geliştirilmesi araştırmacılara sunulan bir diğer öneridir.

Kariyer uyumluluğu geliştirilebilir bir psikososyal özelliktir ve bu bağlamda uygulayıcıların yapabileceği çeşitli çalışmalar mevcuttur. Araştırma sonucunda elde edilen kariyer uyumluluğunun güç, özgürlük ve eğlence ihtiyaçları ve azim tarafından yordanması bağlamında uygulayıcılara doğrudan ve dolaylı şekilde bu özelliklerin geliştirileceği çalışmalar önerilmektedir. Uygulayıcılar ilk olarak üniversite öğrencilerinin psikolojik ihtiyaçlarını azimlerini anlamaları ve nasıl geliştireceklerini keşfetmelerine yönelik psikososyal eğitim programları hazırlayabilir ve doğrudan üniverisite öğrencilerine uygulanabilirler. Bu uygulamalarla öğrenciler psikolojik ihtiyaçlarını anlamlandırma ve tatmin etme şansı yakalayacaklar ayrıca azimlerini geliştirerek karşılaştıkları kariyer engellerini aşmada kendilerini yetkin hissedeceklerdir. Uygulayıcılara sunulan ikinci öneri ise üniversite ekosisteminin tamanını kapsayacak niteliktedir. Üniversite ekosistemi içerisindeki unsurlar (öğretim elemanlarının bakış açısı, sosyal imkanlar, kütüphane vb.) örtük bir şekilde öğrencilerin psikolojik ihtiyaçlarını doyuracak ve azimlerini geliştirecek şekilde tasarlanmalıdır. Öğrenci üniversite içerisinde kendini yetkin hissederek güç ihtiyacını, bilgiye ulaşarak ve seçeneklerini keşferedek özgürlük ve eğlence ihtiyacını doyuracak, engellerle mücadele etmeyi öğrenerek azmini geliştirecektir.

\section{KAYNAKÇA}

Akoğlan Kozak, M., \& Dalkıranoğlu, T. (2013). Mezun öğrencilerin kariyer algılamaları: Anadolu Üniversitesi örneği. Anadolu University Journal of Social Sciences, 13(1), 41-52. Retrieved from http://search.ebscohost.com/login.aspx?direct=true \&db=a9h\&AN=91513228\&site=eds-live

Andreassen, C. S., Hetland, J., \& Pallesen, S. (2010). The relationship between 'workaholism', basic needs satisfaction at work and personality. European Journal of Personality, 24(1), 3-17. doi.org/10.1002/per.737.

Arshadi, N. (2010). Basic need satisfaction, work motivation, and job performance in an industrial company in Iran. Procedia-Social and Behavioral Sciences, 5, 1267-1272. DOI:10.1016/j.sbspro.2010.07.273.

Ayaz, A., \& Pişkin, M. (2017). İş dünyasında başarıya ulaşmış yöneticilerin kariyer örüntülerinin incelenmesi. Uluslararası Iş̧ ve istihdam Kongresi, 14-15 Aralık 2017. Ankara.

Benesová, ` A., Tupa, J., 2017. Requirements for education and qualification of people in industry 4.0. Procedia Manuf. 11, 2195-2202, doi: 10.1016/ j.promfg.2017.07.366

Bilim, Sanayi ve Teknoloji Bakanlığı (2018). Dijital Türkiye yol haritası. https://www.sanayi.gov.tr/tsddtyh.pdf adresinden erişildi.

Bowker, L. (2004). What does it take to work in the translation profession in Canada in the 21st century?: Exploring a database of job advertisements. Meta: Journal des traducteurs/Meta: Translators' Journal, 49(4), 960-972. doi: 10.7202/009804

Broadbridge, A., \& Swanson, V. (2005). Earning and learning: how term-time employment impacts on students' adjustment to university life. Journal of Education and Work, 18(2), 235-249. doi:10.1080/13639080500086008

Büyükgöze-Kavas, A. (2016). Predicting career adaptability from positive psychological traits. The Career Development Quarterly, 64(2), 114125. DOI: $10.1002 /$ cdq.12045

Büyüköztürk, Ş. (2017). Sosyal bilimler için veri analizi el kitabı. istatistik, araştırma deseni SPSS uygulamaları ve yorum. (23.bs.). Ankara: Pegem Akademi.

Büyüköztürk, Ş., Çakmak, E. K., Akgün, Ö. E., Karadeniz, Ş., \& Demirel, F. (2017). Bilimsel araştırma yöntemleri. Pegem. Ankara

Corey, G. (2015). Theory and practice of counseling and psychotherapy. New York: Nelson Education. 
De Vera, M. J., Gavino Jr, J. C., \& Portugal, E. J. (2015). Grit and superior work performance in an Asian context. In Proceedings of 11th International Business and Social Science Research Conference, January 2015.

Demir, Ö. O., \& Ayaz, A. Rehberlik ve Psikolojik Danışma Bölümü Mezunlarının Çalışma Durumlarında Kariyer Uyumluluğunun Rolü. Batı Anadolu Eğitim Bilimleri Dergisi, 10(1), 28-36.

Duckworth, A. (2016). Grit: The Power of Passion and Perseverance. New York: Simon and Schuster.

Duckworth, A. L., \& Quinn, P. D. (2009). Development and validation of the Short Grit Scale (GRIT-S). Journal of personality assessment, 91(2), 166-174. doi.org/10.1080/00223890802634290

Duckworth, A. L., Peterson, C., Matthews, M. D., \& Kelly, D. R. (2007). Grit: perseverance and passion for long-term goals. Journal of personality and social psychology, 92(6), 1087. DOI: 10.1037/0022-3514.92.6.1087

Duffy, R. D. (2010). Sense of control and career adaptability among undergraduate students. Journal of Career Assessment, 18(4), 420-430. doi: 10.1177/1069072710374587

Eryılmaz, A., \& Kara, A. (2019). Öğretmenlerin Öznel İyi Oluşlarıyla Kariyer Uyumlulukları Arasında Amaçlar İçin Mücadele Etmenin Aracı Rolü. Türk Psikolojik Danışma ve Rehberlik Dergisi, 9(52), 1-21.

Eskreis-Winkler, L., Shulman, E. P., Beal, S. A., \& Duckworth, A. L. (2014). The grit effect: Predicting retention in the military, the workplace, school and marriage. Frontiers in psychology, 5. doi.org/10.3389/fpsyg.2014.00036

Eşici, H. (2014). Romantik ilişki kalitesinin erken dönem uyumsuz şemalar, bağlanma ve psikolojik ihtiyaçlar açısından incelenmesi. Yayınlanmamış doktora tezi, Gazi Üniversitesi, Ankara.

Fraenkel, J. R., \&Wallen, N. E. (2009). How to Design and Evaluate Research in Education. Boston, MA: McGraw Hil

Franklin, R. J. (2015). What Leads To Effective Self-Regulation? Origins And Outcomes Of Entrepreneurs'grit. Frontiers of Entrepreneurship Research, 35(4), 1.

Glasser, W. (1998). The quality school: managing students without coercion New York: Harper Collins.

Glasser, W. (1999). Choice theory: A new psychology of personal freedom. Harper Perennial.

Glasser, W. (2000). School violence from the perspective of William Glasser. Professional School Counseling, 4(2), 77.

Guan, Y., Guo, Y., Bond, M. H., Cai, Z., Zhou, X., Xu, J., ... \& Wang, Y. (2014). New job market entrants' future work self, career adaptability and job search outcomes: Examining mediating and moderating models. Journal of Vocational Behavior, 85(1), 136-145. doi.org/10.1016/j.jvb.2014.05.003

Guo, Y., Guan, Y., Yang, X., Xu, J., Zhou, X., She, Z., ... \& Pan, Z. (2014). Career adaptability, calling and the professional competence of social work students in China: A career construction perspective. Journal of Vocational Behavior, 85(3), 394-402. doi.org/10.1016/j.jvb.2014.09.001

Harry, N., \& Coetzee, M. (2013). Sense of coherence, career adaptability and burnout of early-career Black staff in the call centre environment. SA Journal of Industrial Psychology, 39(2), 1-10. dx.doi.org/10.4102/sajip.v39i2.1138

Hogan, M., \& Larkin-Wong, K. (2013). Grit and Mindset. Women Law. J., 98, 11.

Karacan Ozdemir, N., \&Ayaz, A. (2018). Okul psikolojik danışma ve rehberlik programları: Kariyer uyum yetenekleri açısından bir inceleme. Hacettepe Üniversitesi Eğitim Fakültesi Dergisi. Advance online publication. doi: 10.16986/HUJE.2018045437

Karacan-Ozdemir, N., \& Yerin Guneri, O. (2017). The factors contribute to career adaptability of highschool students. Eurasian Journal of Educational Research, 67, 183-198. https://doi.org/10.14689/ ejer.2017.67.11.

Karacan-Özdemir, N., \& Yerin Güneri, O. (2017). The Factors Contribute to Career Adaptability of High-School Students. Eurasian Journal of Educational Research (EJER), (67). http://dx.doi.org/10.14689/ejer.2017.67.11

Karacan-Özdemir, N.,. (2016). The factors contrıbute to career adaptabılity of hıgh school students. Yayınlanmamış doktora tezi, METU, Ankara.

Kim, A. S., DiPlacido, M. P., Kerns, M. C., \& Darnley, R. E. (2018). Industry 4.0: Digitization in Danish Industry. https://digitalcommons.wpi.edu/iqp-all/5185 adresinden erişildi.

Koen, J., Klehe, U. C., Van Vianen, A. E., Zikic, J., \& Nauta, A. (2010). Job-search strategies and reemployment quality: The impact of career adaptability. Journal of Vocational Behavior, 77(1), 126-139. https://doi.org/10.1016/j.jvb.2010.02.004

Kovjanic, S., Schuh, S. C., \& Jonas, K. (2013). Transformational leadership and performance: An experimental investigation of the mediating effects of basic needs satisfaction and work engagement. Journal of Occupational and Organizational Psychology, 86(4), 543-555. DOI:10.1111/joop.12022

Maddi, S. R., Matthews, M. D., Kelly, D. R., Villarreal, B., \& White, M. (2012). The role of hardiness and grit in predicting performance and retention of USMA cadets. Military Psychology, 24(1), 19. https://doi.org/10.1080/08995605.2012.639672

Peterson, C. (2000). The future of optimism. American Psychologist, 55(1), 44.

Rudolph, C. W., Lavigne, K. N., \& Zacher, H. (2017). Career adaptability: A meta-analysis of relationships with measures of adaptivity, adapting responses, and adaptation results. Journal of Vocational Behavior, 98, 17-34. https://doi.org/10.1016/j.jvb.2016.09.002

Sarıçam, H., Çelik, I., \& Oğuz, A. (2015, October). Turkish adaptation of the Short Grit Scale (Grit-S): Validity and reliability study. In The 3rd International Congress on Curriculum and Instruction (pp. 22-24).

Savickas, M. L. (2005).The theory and practice of career construction. Career development and counseling: Putting theory and research to work, 1, 42-70.

Savickas, M. L. (2011). Constructing careers: Actor, agent, and author. Journal of Employment Counseling, 48(4), 179. 
Savickas, M. L. (2013). The 2012 Leona Tyler Award Address: Constructing Careers Actors, Agents, and Authors. The Counseling Psychologist, 41(4), 648-662. https://doi.org/10.1177/0011000012468339

Savickas, M. L., \& Porfeli, E. J. (2011). Revision of the career maturity inventory: The adaptability form. Journal of Career Assessment, 19(4), 355-374. https://doi.org/10.1177/1069072711409342

Savickas, M. L., \& Porfeli, E. J. (2012). Career Adapt-Abilities Scale: Construction, reliability, and measurement equivalence across 13 countries. Journal of Vocational Behavior, 80(3), 661-673. https://doi.org/10.1016/j.jvb.2012.01.011

Siddoway, R. (2013). Grit. New York: The Rosen Publishing Group.

Silman, F. (2014). Work-related basic need satisfaction as a predictor of work engagement among academic staff in Turkey. South African Journal of Education, 34(3), 01-05.

Siyez, D. M., \& Yusupu, R. (2015). Üniversite öğrencilerinde kariyer uyumluluğu ve kariyer iyimserliğinin cinsiyet rolü değişkenine göre incelenmesi. ISGUC The Journal of Industrial Relations and Human Resources, 17(1), 75-88. DOI: 10.4026/1303-2860.2015.0270.x

Suzuki, Y., Tamesue, D., Asahi, K., \& Ishikawa, Y. (2015). Grit and work engagement: A cross-sectional study. PloS one, 10(9), e0137501. doi:10.1371/journal.pone.0137501

Tabachnick, B. G., \& Fidell, L. S. (2015). Çok değişkenli istatistiklerin kullanımı (M. Baloğlu, çev.). Ankara. Nobel

Trilling, B., \& Fadel, C. (2009). 21st century skills: Learning for life in our times. New York, NY: John Wiley

TÜiK (2018). İşücü Istatistikleri, Ağustos 2018. http://www.tuik.gov.tr/HbGetirHTML.do?id=27690. adresinden erişildi.

Van den Broeck, A., Vansteenkiste, M., De Witte, H., \& Lens, W. (2008). Explaining the relationships between job characteristics, burnout, and engagement: The role of basic psychological need satisfaction. Work \& Stress, 22(3), 277-294. https://doi.org/10.1080/02678370802393672

Verbruggen, M., De Cooman, R., \& Vansteenkiste, S. (2015). When and why are internal job transitions successful? Transition challenges, hindrances, and resources influencing motivation and retention through basic needs satisfaction. Group \& Organization Management, 40(6), 744-775. DOI: 10.1177/1059601115595935

Wubbolding, R. E. (2013). Reality therapy for the 21st century. Routledge. 